\title{
Antibacterial Activity of Silver Nanoparticles Synthesized by Bark Extract of Syzygium cumini
}

\author{
Ram Prasad and Vyshnava Satyanarayana Swamy \\ Amity Institute of Microbial Technology, Amity University Uttar Pradesh, Sector 125, Noida 201303, India \\ Correspondence should be addressed to Ram Prasad; rprasad@amity.edu
}

Received 31 January 2013; Revised 15 March 2013; Accepted 3 April 2013

Academic Editor: Amir Kajbafvala

Copyright (C) 2013 R. Prasad and V. S. Swamy. This is an open access article distributed under the Creative Commons Attribution License, which permits unrestricted use, distribution, and reproduction in any medium, provided the original work is properly cited.

The unique property of the silver nanoparticles having the antimicrobial activity drags the major attention towards the present nanotechnology. The environmentally nontoxic, ecofriendly, and cost-effective method that has been developed for the synthesis of silver nanoparticles using plant extracts creates the major research interest in the field of nanobiotechnology. The synthesized silver nanoparticles have been characterized by the UV-visible spectroscopy, atomic force microscopy (AFM), and scanning electron microscopy (SEM). Further, the antibacterial activity of silver nanoparticles was evaluated by well diffusion method, and it was found that the biogenic silver nanoparticles have antibacterial activity against Escherichia coli (ATCC 25922), Staphylococcus aureus (ATCC 29213), Pseudomonas aeruginosa (ATCC 27853), Azotobacter chroococcum WR 9, and Bacillus licheniformis (MTCC 9555).

\section{Introduction}

The broad spectrum of nanotechnology is important in the major fields of biology, chemistry, physics, and material sciences. Nanotechnology deals with the study of materials at the nanometers $[1,2]$. The day to day development of nanotechnology creates a major interest in the development and fabrications of different dimensioned nanoparticles [3]. The nanomaterials can be synthesized by different methods including chemical, physical, irradiation, and biological methods. The development of new chemical or physical methods has resulted in environmental contaminations, since the chemical procedures involved in the synthesis of nanomaterials generate a large amount of hazardous byproducts [4]. Thus, there is a need for "green nanotechnology" that includes a clean, safe, ecofriendly, and environmentally nontoxic method of nanoparticle synthesis, and in this method there is no need to use high pressure, energy, temperature, and toxic chemicals $[5,6]$. The biological methods include synthesis of nanomaterial's from the extracts of plant, bacterial, fungal species, and so forth. The synthesis of nanoparticles from the plant extracts is considered to be a process [7]. The preparation and maintenance of fungal and bacterial cultures are time consuming and require aseptic conditions and large manual skills to maintain the cultures [8].

Plant extracts include bark, root, leaves, fruit, flowers, rhizoids, and latex and are used to synthesize the nanoparticles. These nanoparticles show different dimensions including the size, shape, and dispersion which have more efficacy than those synthesized from the chemical and physical procedures. Therefore, the use of green plants for similar nanoparticle biosynthesis methodologies is an exciting possibility which has compatibility for pharmaceutical and other biomedical applications, as they do not use toxic chemicals for the synthesis of nanoparticles $[9,10]$.

Nanoparticles had a wide variety of application in the major fields of medicine, electronics, therapeutics, and diagnostic agents. Silver nanoparticles have wide application in biomedical science like treatment of burned patients, antimicrobial activity and used the targeted drug delivery, and so forth [11]. Nowadays the nanoparticles are coated on the medical appliances, food covering sheets, and cans for storing the beverages and food [12-14]. However, there are many problems and toxicity of using metal oxide nanoparticles on the human health. Use of plants for the synthesis of nanoparticles does not require high energy, temperatures, and it is easily 


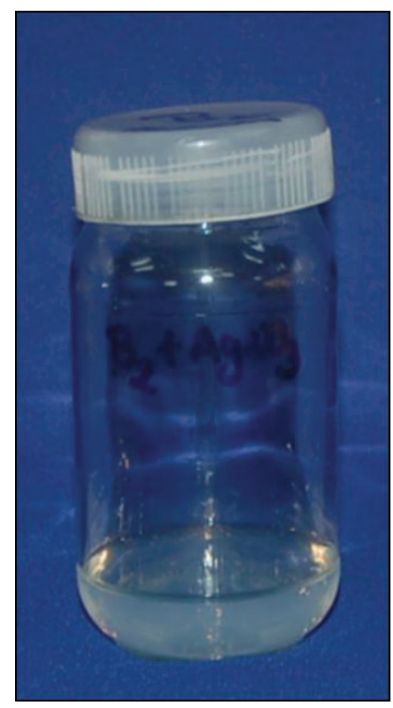

(a)

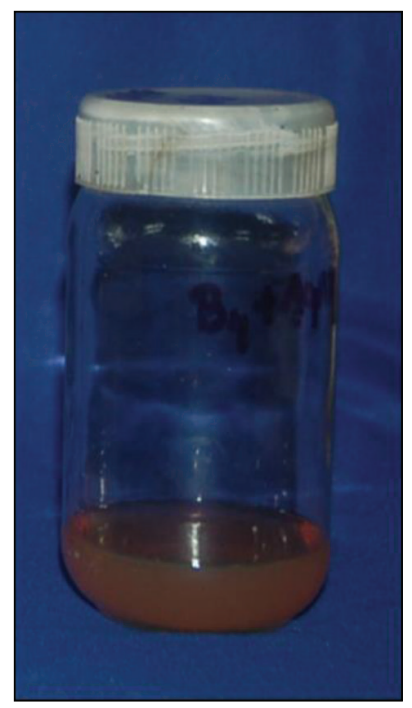

(b)

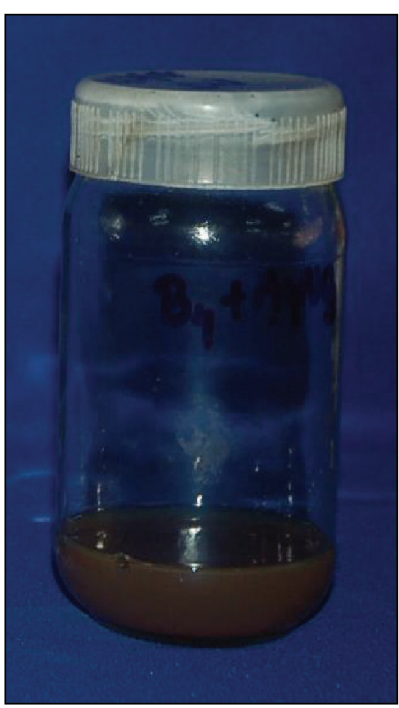

(c)

FIGURE 1: Syzygium cumini bark extract sample. Change in the color of the solution from brown to dark brown. (a) Silver nitrate solution, (b) reaction mixture, and (c) change in the color of the solution.

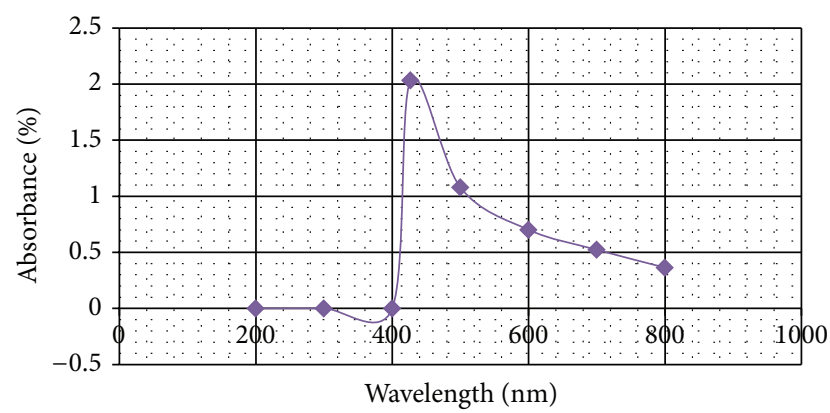

FIGURE 2: UV-visible spectrum of silver nanoparticles.

scaled up for large scale synthesis, and it is cost effective too [15-17].

Syzygium cumini is a medicinal plant available in the tropical forests and is used for treatment of diabetes. The leaves and bark are used for controlling blood pressure and gingivitis [14]. The plant contains a variety of phytochemical compounds such as phenols, tannins, alkaloids, glycosides, amino acids, and flavones, and these molecules are expected to self-assemble and cap the metal nanoparticles formed in their presence and thereby induce some shape control during metal ion reduction [18]. In this study we used the silver nanoparticles synthesized from the bark extract of S. cumini and its antibacterial effect on the bacteria, namely, Escherichia coli (ATCC 25922), Staphylococcus aureus (ATCC 29213), Pseudomonas aeruginosa (ATCC 27853), Azotobacter chroococcum WR 9, and Bacillus licheniformis (MTCC 9555).

\section{Materials and Methods}

2.1. Chemicals. All analytical reagents and media components were purchased from HiMedia (Mumbai, India) and Sigma Chemicals (St. Louis, MO, USA).

2.2. Preparation of Plant Extract. The fresh bark of Syzygium cumini was collected and kept in hot air oven for drying at $60^{\circ} \mathrm{C}$ for six hours. The dried bark was chopped into fine pieces with the help of mixer grinder. It was collected, weighed for $2.5 \mathrm{~g}$, and then mixed in $100 \mathrm{~mL}$ of double distilled water. This mixture was boiled at $60^{\circ} \mathrm{C}$ in the water bath for one hour. The solution was cooled at room temperature and filtered by Whatman filter paper No. 1. The filtrate was collected and stored at $4^{\circ} \mathrm{C}$ for further experiment.

2.3. Synthesis of Silver Nanoparticles. Silver nanoparticles $\left(\mathrm{AgNO}_{3}\right)$ were synthesized by reducing the freshly prepared $1 \mathrm{mM}$ silver nitrate and stored under dark conditions with the bark extract. The reaction mixture was prepared in ratio of $9: 1(\mathrm{~V} / \mathrm{V})$ of freshly prepared silver nitrate solution and bark extract, respectively. The initial color of the solution was observed.

2.4. UV-Visible Spectroscopy. The silver nanoparticles show the plasmon resonance at 400 to $450 \mathrm{~nm}$ in the UV-Visible spectrum. The UV-Visible spectrum of synthesized silver nanoparticles was analysed by spectrophotometer (LAB INDIA UV 300+).

2.5. Atomic Force Microscopy. Atomic force microscopy is an advanced characterization technique to identify the size, 


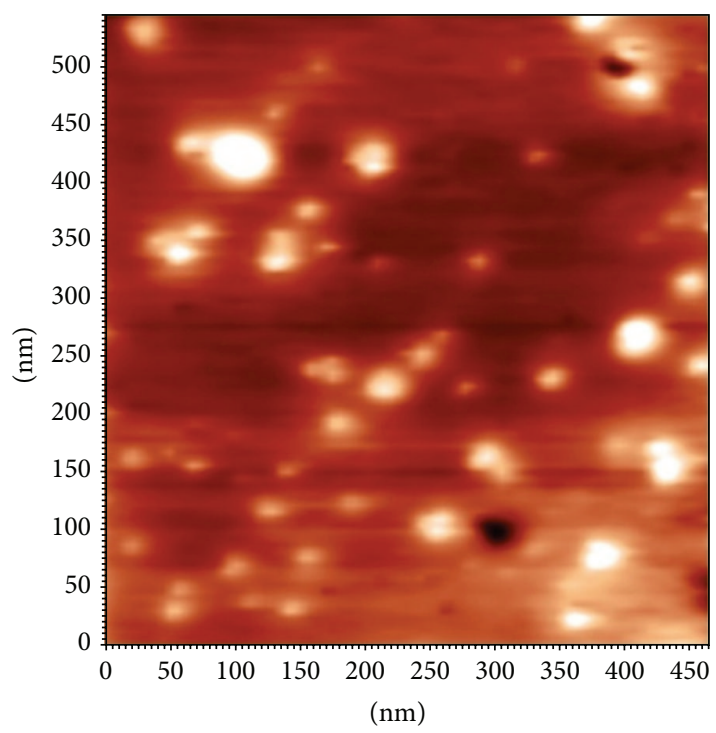

(a)

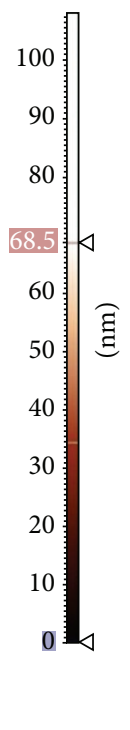

FIgURE 3: Atomic force microscopy. (a) Image of synthesized silver nanoparticles and (b) its histogram.

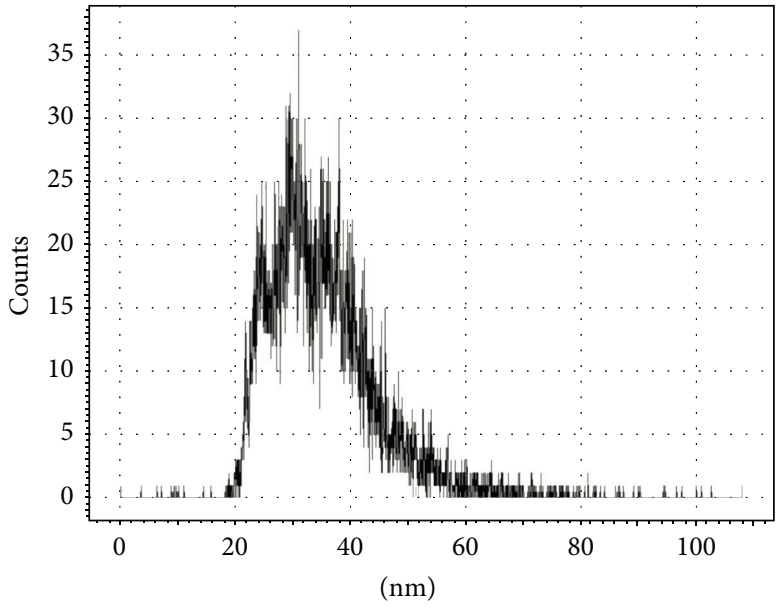

(b)

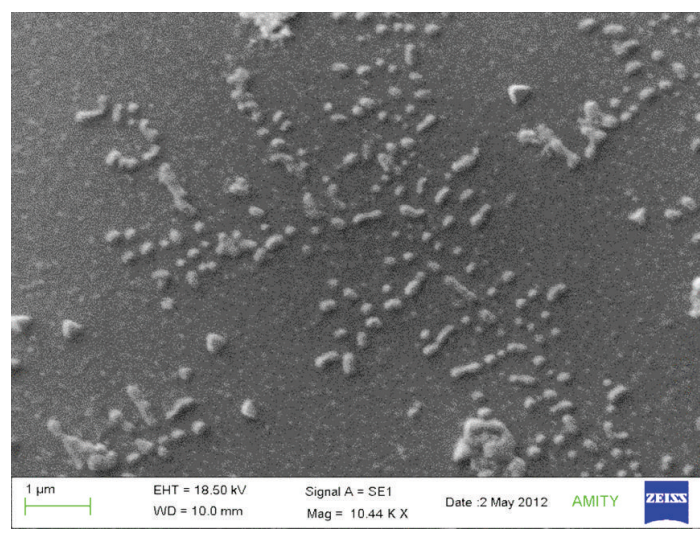

FIGURE 4: SEM images of silver nanoparticles synthesized by $S$. cumini bark extract.

shape, and dispersion of the silver nanoparticles. In order to characterize the silver nanoparticles, the sample was prepared by sonication at room temperature for about 15 minutes in the ultrasonicator. Then the sample solution was dried as a thin layer on mica-based glass slide which was used to view under the AFM Model NT-MDA Solver.

2.6. Scanning Electron Microscopy. SEM analysis of the silver nanoparticles provides the information regarding the dimensions including the surface, shape, and size. The sample was prepared by sonicating the sample solution for 15 minutes at room temperature. A small drop of sonicated sample was dried on a glass slide, and it was coated by gold and observed under ZEISS EVO HD SEM.

2.7. Antibacterial Property. The antibacterial property of the silver nanoparticles was determined by using the bacterial species including the pathogenic bacteria such as Escherichia coli (ATCC 25922), Staphylococcus aureus (ATCC 29213), Pseudomonas aeruginosa (ATCC 27853), Azotobacter chroococcum WR 9, and Bacillus licheniformis (MTCC 9555), by the well diffusion method [14]. The different concentrations used were at low concentrations $(2,5,10$, and $15 \mu \mathrm{L})$ and at higher concentrations $(25,50,75$, and $100 \mu \mathrm{L})$ for the identification of antimicrobial activity of the above bacterial species. All the plates were incubated at $37^{\circ} \mathrm{C}$ for 24 hours, and the zone of inhibition of bacteria was measured.

\section{Results and Discussion}

The green synthesis of silver nanoparticles using S. cumini bark extract was successfully carried out, as the change in the color of the solution from yellowish brown to dark brown color exhibits the reduction of the silver nitrate in aqueous solution due to excitation of surface plasmon vibrations in silver nanoparticles [19]. During this reaction process the $\mathrm{pH}$ of the solution changes from 5.93 to 5.72, which implies that the reaction occurs under acidic condition. This complete reaction occurs in seven hours. The brown to dark brown color change of the reaction mixture indicated the formation of silver nanoparticles (Figure 1).

The formation of silver nanoparticles was confirmed through measurement of UV-Visible spectrum of the reaction mixture. The UV-Visible spectrophotometric analysis of colloidal reaction mixture of silver nanoparticles synthesized using S. cumini bark showed sharp peak at $427 \mathrm{~nm}$ in the spectrum, and broadening of peak indicated that the particles are polydispersed [20] (Figure 2). The efficiency of this method was tested for stability also. The reaction mixture was stored for 45 days, and no precipitation in the solution was observed. It was also checked through UV-Vis absorption on regular interval. 

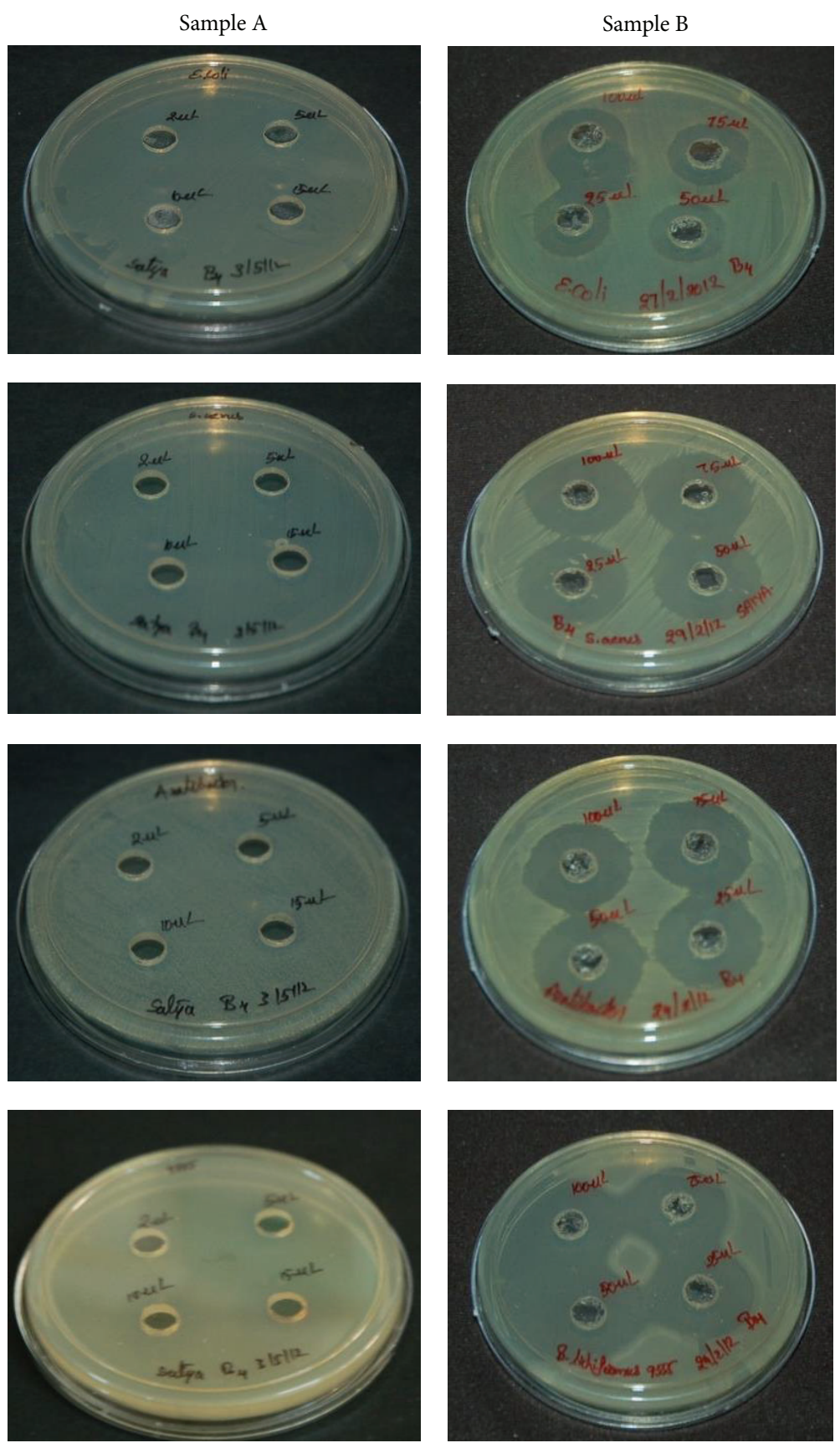

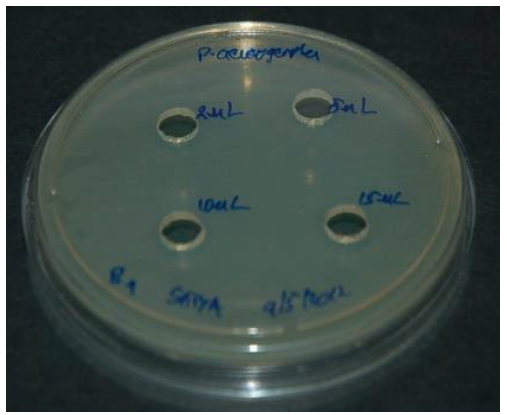

(a)

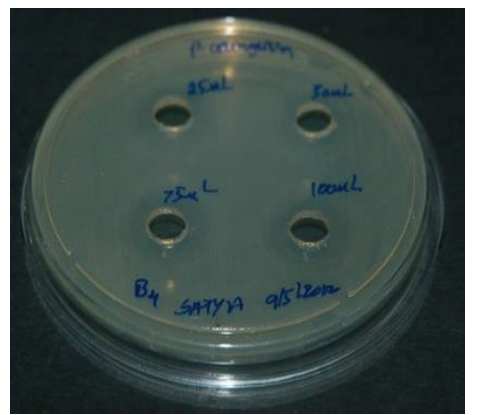

(b)

Figure 5: Antibacterial effects varying the concentrations of silver nanoparticles samples, (a) lower concentrations $(2,5,10$, and $15 \mu \mathrm{L})$ and (b) Higher concentrations $(25,50,75$, and $100 \mu \mathrm{L})$. 


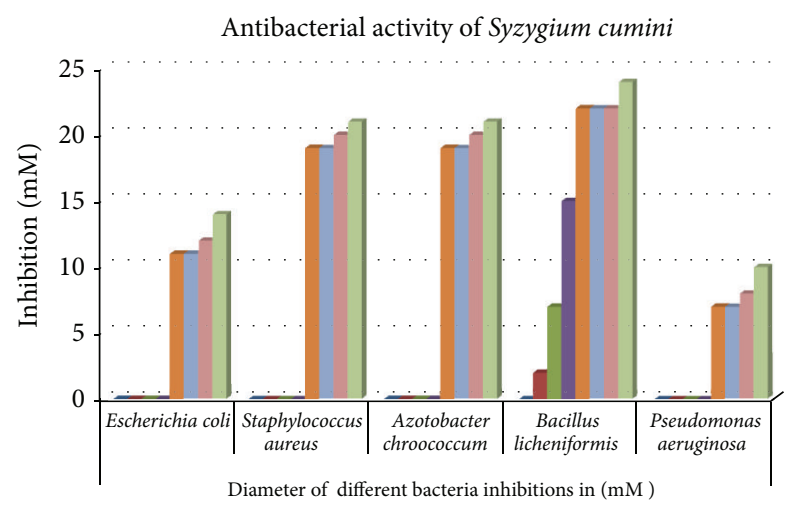

FIGURE 6: Antibacterial activity of Syzygium cumini, with different concentrations ranging from $2,5,10,15,25,50,75$, and $100 \mu \mathrm{L}$.

The atomic force microscopy (AFM) results display the surface morphology of the monodispersed silver nanoparticles using S. cumini bark extract. The particle size of the silver nanoparticles that ranges from 20 to $60 \mathrm{~nm}$ was observed. The topographical image of silver nanoparticles indicated that they are agglomerated and formed distinct nanoparticles (Figures 3(a) and 3(b)). The bright spots on the micrograph indicated that the nanoparticles are spherical in shape.

The biosynthesized silver nanoparticles were characterized by scanning electron microscopy for their morphology and size. The SEM micrograph reveals that the synthesized silver nanoparticles have spherical morphology with size range from 20 to $60 \mathrm{~nm}$ and also indicated that the particles are well separated showing no agglomeration (Figure 4).

The different species of bacteria show zone of inhibition in the well diffusion method of antimicrobial activity. The different patterns of the zone of inhibitions are observed in Figure 5. Synthesized silver nanoparticles showed antibacterial activity against both Gram positive and negative bacteria (Figure 6). The highest zone of inhibition was observed for Bacillus licheniformis even at lower concentration. The exact mechanism of the inhibition of the bacteria is still unknown, but some hypothetical mechanisms show that the inhibition is due to ionic binding of the silver nanoparticles on the surface of the bacteria which creates a great intensity of the proton motive force, and the one hypothesis from the research states that the silver nanoparticles invade the bacterial cell and bind to the vital enzymes containing thiol groups $[12,21,22]$. Also, the findings of Sereemaspun et al. (2008) [23] suggested the inhibition of oxidation-based biological process by penetration of metallic nanosized particles across the microsomal membrane $[23,24]$. The molecular basis for the biosynthesis of these silver crystals speculated that the organic matrix contains silver binding properties that provide amino acid moieties that serve as the nucleation sites [25,26].

\section{Conclusions}

The biological synthesis of the silver nanoparticles is rapid, ecofriendly, cost-effective, and simple method of synthesis. In the present study-silver nanoparticles are synthesized at room temperature within a less span of time. The synthesized silver nanoparticles were characterized by UV-visible spectrometer, AFM, and SEM analysis. The size of the nanoparticles ranges from 20 to $60 \mathrm{~nm}$ with spherical shape. AFM and SEM reveal that the synthesized silver nanoparticles are well dispersed showing no agglomeration. These nanoparticles showed a broad spectrum antimicrobial activity against both Gram positive and Gram negative bacteria. Investigation on the antibacterial activity of synthesized silver nanoparticles using cumini extract against Staphylococcus aureus and Bacillus licheniformis reveals high potential as antimicrobial agent in pharmaceutical, food, and cosmetic industries.

\section{Conflict of Interests}

The authors declare that they have no conflict of interests.

\section{Acknowledgments}

The authors are thankful to Drs. Gaurav Raikhy and Ravi Mani Tripathi, Amity University, India, for critically reading the paper and analyzing the data.

\section{References}

[1] E. K. Elumalai, T. N. V. K. V. Prasad, J. Hemachandran, T. S. Viviyan, T. Thirumalai, and E. David, "Extracellular synthesis of silver nanoparticles using leaves of Euphorbia hirta and their antibacterial activities," Journal of Pharmaceutical Sciences and Research, vol. 2, no. 9, pp. 549-554, 2010.

[2] A. V. Singh, R. Patil, M. B. Kasture, W. N. Gade, and B. L. V. Prasad, "Synthesis of Ag-Pt alloy nanoparticles in aqueous bovine serum albumin foam and their cytocompatibility against human gingival fibroblasts," Colloids and Surfaces B, vol. 69, no. 2, pp. 239-245, 2009.

[3] C. Marambio-Jones and E. M. V. Hoek, "A review of the antibacterial effects of silver nanomaterials and potential implications for human health and the environment," Journal of Nanoparticle Research, vol. 12, no. 5, pp. 1531-1551, 2010.

[4] M. Zhang, M. Liu, H. Prest, and S. Fischer, "Nanoparticles secreted from ivy rootlets for surface climbing," Nano Letters, vol. 8, no. 5, pp. 1277-1280, 2008.

[5] S. Jeong, S. Yeo, and S. Yi, "Antibacterial characterization of silver nanoparticles against E. coli ATCC-15224," Journal of Material Science, vol. 40, article 5407, 2005.

[6] N. Savithramma, R. M. Linga, K. Rukmini, and D. P. Suvarnalatha, "Antimicrobial activity of silver nanoparticles synthesized by using medicinal plants," International Journal of ChemTech Research, vol. 3, no. 3, pp. 1394-1402, 2011.

[7] A. Saxena, R. M. Tripathi, and R. P. Singh, "Biological synthesis of silver nanoparticles by using onion Allium cepa extract and their antibacterial activity," Digest Journal of Nanomaterials and Biostructures, vol. 5, no. 2, pp. 427-432, 2010.

[8] S. Schultz, D. R. Smith, J. J. Mock, and D. A. Schultz, "Singletarget molecule detection with nonbleaching multicolor optical immunolabels," Proceedings of the National Academy of Sciences of the United States of America, vol. 97, no. 3, pp. 996-1001, 2000.

[9] K. Vijayaraghavan and S. P. K. Nalini, "Biotemplates in the green synthesis of silver nanoparticles," Biotechnology Journal, vol. 5, no. 10, pp. 1098-1110, 2010. 
[10] R. M. Crooks, M. Zhao, L. Sun, V. Chechik, and L. K. Yeung, "Dendrimer-encapuslated metal nanoparticles: synthesis, characterization and application to catalysis," American Chemical Society, vol. 34, no. 3, pp. 181-190, 2001.

[11] A. Singh, D. Jain, M. K. Upadhyay, N. Khandelwal, and H. N. Verma, "Green synthesis of silver nanoparticles using Argemone mexicana leaf extract and evaluation of their antimicrobial activities," Digest Journal of Nanomaterials and Biostructures, vol. 5, no. 2, pp. 483-489, 2010.

[12] V. K. Sharma, R. A. Yngard, and Y. Lin, "Silver nanoparticles: green synthesis and their antimicrobial activities," Advances in Colloid and Interface Science, vol. 145, no. 1-2, pp. 83-96, 2009.

[13] K. S. Prasad, D. Pathak, A. Patel et al., "Biogenic synthesis of silver nanoparticles using Nicotiana tobaccum leaf extract and study of their antibacterial effect," African Journal of Biotechnology, vol. 10, no. 41, pp. 8122-8130, 2011.

[14] P. Ram, V. S. Swamy, P. K. Suranjit, and V. Ajit, "Biogenic synthesis of silver nanoparticles from the leaf extract of Syzygium cumini (L.)," International Journal of Pharma and Bio Sciences, vol. 3, no. 4, pp. 745-752, 2012.

[15] S. Ghosh, S. Patil, M. Ahire et al., "Synthesis of silver nanoparticles using Dioscorea bulbifera tuber extract and evaluation of its synergistic potential in combination with antimicrobial agents," International Journal of Nanomedicine, vol. 7, pp. 483-496, 2012.

[16] P. S. Vankar and D. Shukla, "Biosynthesis of silver nanoparticles using lemon leaves extract and its applications for antimicrobial finish on fabric," Applied Nanoscience, vol. 2, pp. 163-168, 2012.

[17] K. S. Mukunthan, E. K. Elumalai, T. N. Patel, and V. R. Murthy, "Catharanthus roseus: a natural source for the synthesis of silver nanoparticles," Asian Pacific Journal of Tropical Biomedicine, pp. 270-274, 2011.

[18] N. Ahmad, S. Sharma, M. K. Alam et al., "Rapid synthesis of silver nanoparticles using dried medicinal plant of basil," Colloids and Surfaces B, vol. 81, no. 1, pp. 81-86, 2010.

[19] S. S. Shankar, A. Rai, B. Ankamwar, A. Singh, A. Ahmad, and M. Sastry, "Biological synthesis of triangular gold nanoprisms," Nature Materials, vol. 3, no. 7, pp. 482-488, 2004.

[20] V. S. Swamy and P. Ram, "Green synthesis of silver nanoparticles from the leaf extract of Santalum album and its antimicrobial activity," Journal of Optoelectronic and Biomedical Materials, vol. 4, no. 3, pp. 53-59, 2012.

[21] C. Ramteke, T. Chakrabarti, B. K. Sarangi, and R. A. Pandey, "Synthesis of silver nanoparticles from the aqueous extract of leaves of Ocimum sanctums for enhanced antibacterial activity," Journal of Chemistry, vol. 2013, Article ID 278925, 7 pages, 2013.

[22] S. Kavita, J. Santhanalakshmi, and B. Viswanathan, "Green synthesis of silver nanoparticles using Polyalthia longifolia leaf extract along with D-Sorbitol: Study of Antibacterial Activity," Journal of Nanotechnology, vol. 2011, Article ID 152970, 5 pages, 2011.

[23] A. Sereemaspun, P. Hongpiticharoen, R. Rojanathanes, P. Maneewattanapinyo, S. Ekgasit, and W. Warisnoicharoen, "Inhibition of human cytochrome P450 enzymes by metallic nanoparticles: a preliminary to nanogenomics," International Journal of Pharmacology, vol. 4, no. 6, pp. 492-495, 2008.

[24] R. M. Linga and N. Savithramma, "Antimicrobial activity of silver nanoparticles synthesized by using stem extract of Svensonia hyderobadensis (Walp.) mold-a rare medicinal plant," Research in Biotechnology, vol. 3, no. 3, pp. 41-47, 2012.

[25] N. Prabhu, T. R. Divya, and G. Yamuna, "Synthesis of silver phyto nanoparticles and their antibacterial efficacy," Digest
Journal of Nanomaterials and Biostructures, vol. 5, no. 1, pp. 185$189,2010$.

[26] N. Savithramma, M. Linga Rao, K. Rukmini, and P. Suvarnalatha Devi, "Antimicrobial activity of silver nanoparticles synthesized by using medicinal plants," International Journal of ChemTech Research, vol. 3, no. 3, pp. 1394-1402, 2011. 

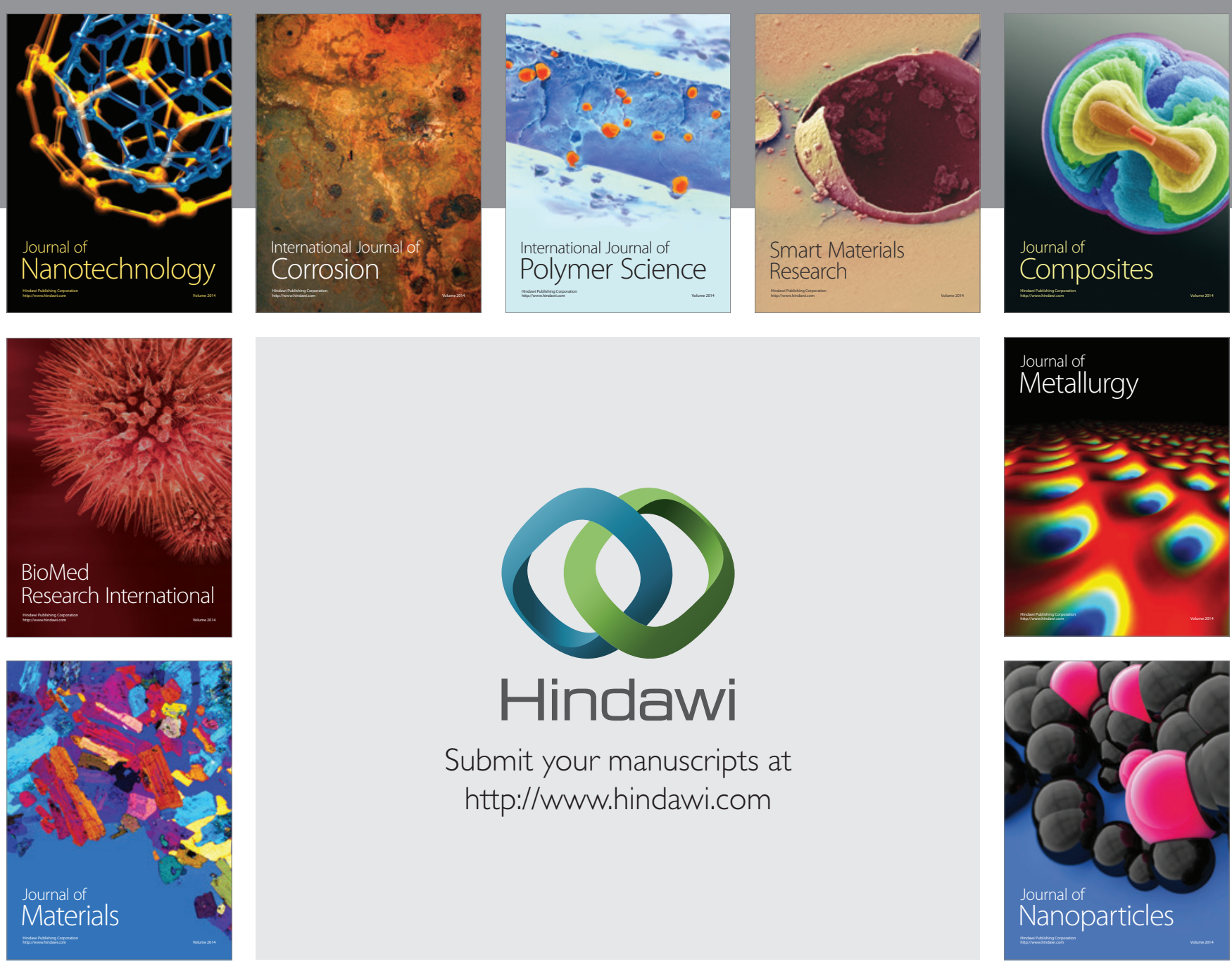

Submit your manuscripts at http://www.hindawi.com
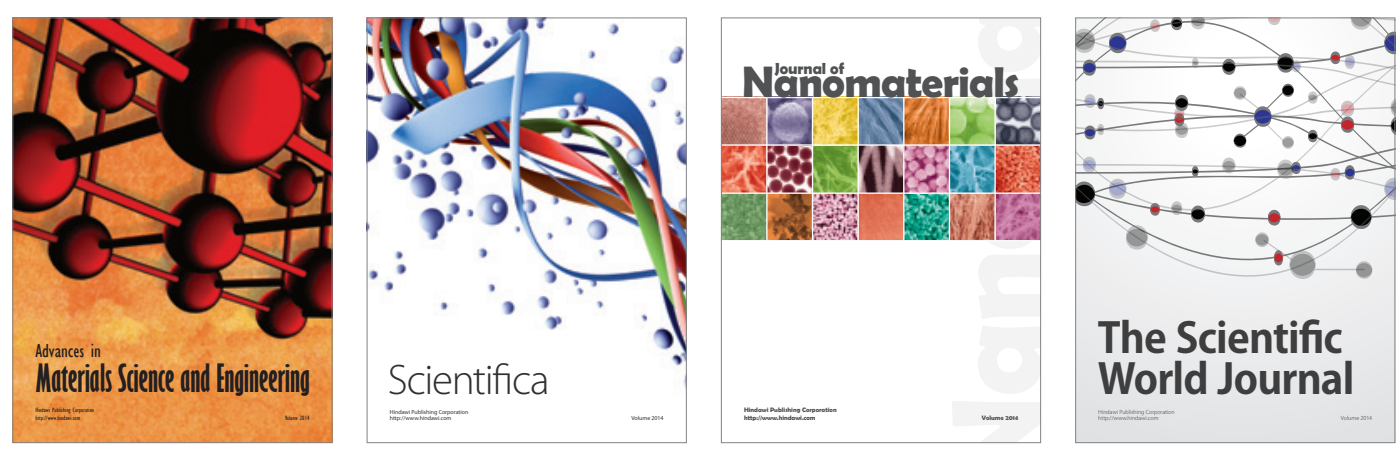

\section{The Scientific World Journal}
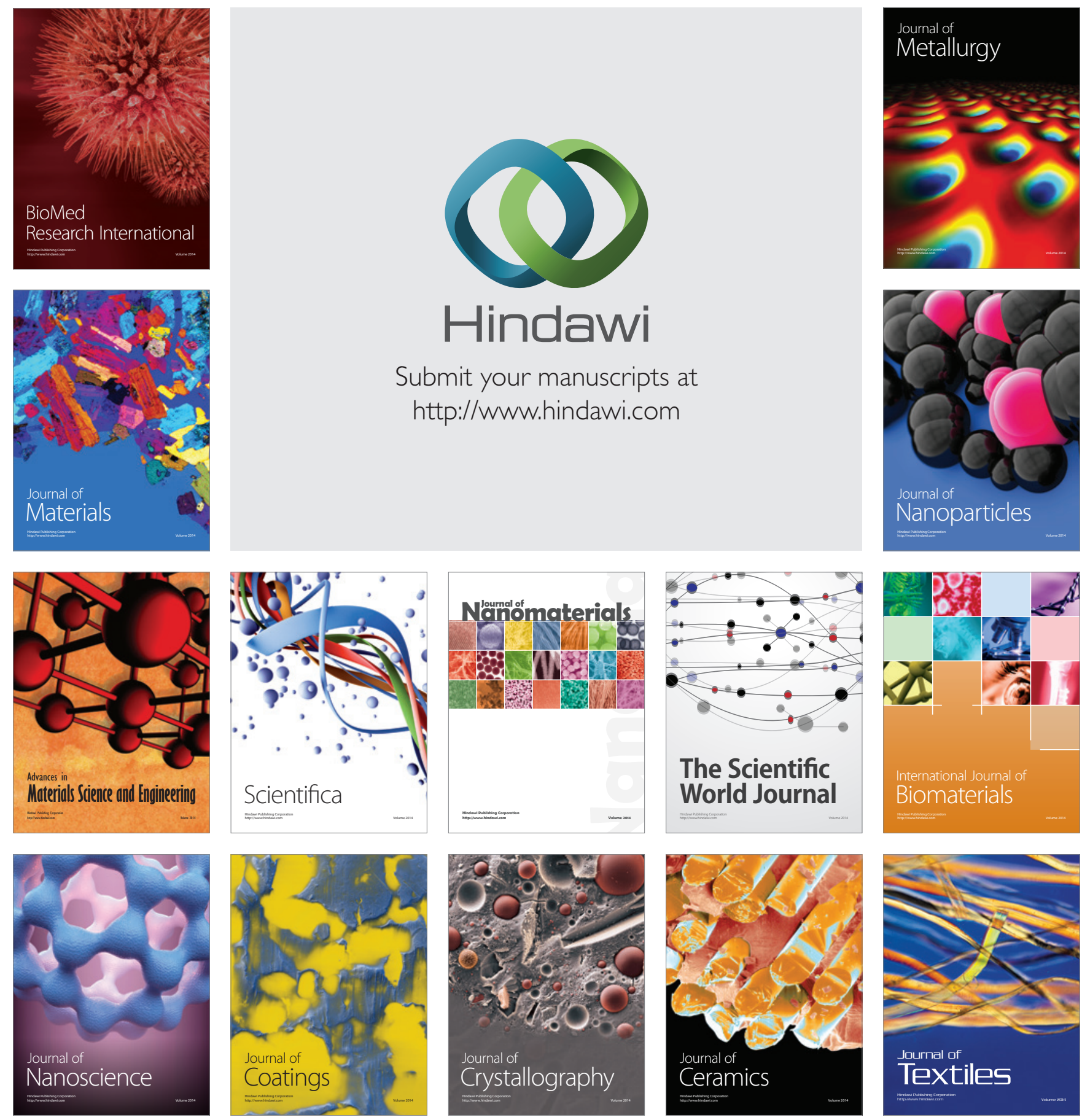